\title{
A PRÁTICA VIEWPOINTS NA ESCOLA: UMA PROPOSTA DE TRABALHO CORPORAL NA DISCIPLINA DE ARTES ${ }^{1}$
}

Fabiano Lodi $^{2}$

RESUMO: Este artigo apresenta algumas práticas utilizadas em um estágio curricular do Curso de Graduação em Artes Cênicas da UDESC, realizado em 2007 em uma escola da rede pública de ensino, em Florianópolis. Na disciplina curricular de Artes foi utilizada a prática Viewpoints, desenvolvida pela diretora teatral americana Anne Bogart, como ferramenta metodológica de ensino de teatro, buscando repensar práticas corporais do cotidiano através da experimentação artística em sala de aula de princípios técnicos de expressividade corporal.

PALAVRAS-CHAVE: Viewpoints, teatro na escola, estágio curricular, prática corporal.

O projeto apresentado neste artigo aconteceu no segundo semestre de 2007, na disciplina Teatro na Escola: Estágio III ${ }^{3}$, onde os acadêmicos matriculados devem realizar vinte horas de prática pedagógica na função de professor na disciplina de Artes, dentro da grade curricular da escola que o acolhe ${ }^{4}$. A disciplina foi ministrada pela Professora Msc. Heloise Vidor e a orientação do estágio foi feita pela Professora Msc. Marisa Naspolini.

Decidi por desenvolver as atividades na Escola Municipal de Educação Básica Henrique Veras, no bairro Canto dos Araçás, durante as aulas de Artes da oitava série, turma 81 do Ensino Fundamental, às quartas-feiras das 07h50 às 09h20 de agosto e 07 de novembro de 2007.

A prática realizada neste estágio está ligada ao projeto de pesquisa $O$ Corpomente em cena: as ações físicas do ator/bailarino, no qual investigamos os Viewpoints ${ }^{6}$, prática sistematizada pela diretora teatral americana Anne Bogart, que a define como "uma

\footnotetext{
${ }^{1}$ Este artigo é resultado final do projeto de pesquisa $O$ corpomente em cena: as ações físicas do ator/bailarino (2007/2008), desenvolvida no Centro de Artes (CEART) da Universidade do Estado de Santa Catarina (UDESC), coordenado pela Professora Dra. Sandra Meyer Nunes.

${ }^{2}$ Participam deste projeto de pesquisa a orientadora Sandra Meyer e os bolsistas IC Volmir Cordeiro e Leticia Martins e os voluntários Ana Carolina Leimann, Anderson Luis do Carmo e Fabiano Lodi.

${ }^{3}$ Disciplina curricular e obrigatória oferecida na $7^{\mathrm{a}}$ fase do curso de Licenciatura em Educação Artística, com habilitação em Artes Cênicas, da Universidade do Estado de Santa Catarina - UDESC.

${ }^{4}$ Por orientação da Professora Msc. Heloise Vidor deveríamos priorizar escolas próximas da Universidade, para facilitar a visitação dos orientadores de estágio às nossas aulas. Para isso, ela nos ofereceu uma lista de tais escolas, que já haviam recebido estagiários anteriormente, o que facilitava a entrada em campo.

${ }^{5}$ Este horário ocupava uma aula-faixa, ou seja, duas aulas seguidas da mesma disciplina. Eram as primeiras aulas do dia.

${ }^{6} \mathrm{~A}$ tradução literal deste termo é pontos de vista, porém é comum entre os praticantes a utilização do termo no seu idioma original, como substantivo próprio, iniciando com letra maiúscula.
} 
filosofia traduzida em uma técnica para treinar performers, construir conjuntos e criar movimento para o palco" $(2005$, p. 07).

Oriunda da dança moderna e dos primeiros questionamentos que originaram o pensamento pós-moderno na dança ${ }^{7}$, a sistematização dos Viewpoints permite ao coordenador de uma prática corporal a diversidade de associações entre atividade física e artística, identificando socialmente princípios trabalhados nas aulas, bem como discutindo o nosso comportamento corporal nas aulas, na rua, em casa, com os amigos, entre outros. O apontamento feito por Danilo Santos de Miranda (2004) acerca do processo educativo no trabalho do coreógrafo Ivaldo Bertazzo me encorajou a colocar em prática minha proposição:

Na diversidade do corpo, expressão concreta da diversidade de gestos, traduz-se a multiplicidade de pensares, imagens, sonhos e desejos, cada qual respeitado em sua integridade, particularidade e autonomia. Constrói-se um movimento de harmonia praticando o improvável - a reunião do diferente no comum, do semelhante no diverso (MIRANDA, 2004, p. 05).

Essas associações eram estimuladas em todas as aulas e algumas delas se materializaram em forma de relatórios por mim solicitados em alguns encontros.

Eu relaciono as brincadeiras feitas hoje com o trânsito porque no trânsito as pessoas têm que ter paciência e calma para sair daquele lugar e todos tem que trabalhar em conjunto. Eu gosto das aulas dadas pelo professor porque nós temos que usar tudo porque em esportes em conjunto nós usaremos. ${ }^{8}$

Bogart afirma que Viewpoints "representa um nítido processo [...] que é nãohierárquico, prático e colaborativo por natureza" (BOGART, 2005, p. 15). Neste sentido, os Viewpoints como prática teatral na disciplina de Artes na escola se configuraram como um caminho para o olhar sobre a relação com o espaço que os envolve, com o próprio

\footnotetext{
${ }^{7}$ Bogart (2005) explica que os Viewpoints são desdobramentos dos Six Viewpoints [espaço, história, tempo, emoção, movimento e forma], sistematizados por Mary Overlie, na década de 1970. Overlie foi influenciada pelas propostas experimentais de um grupo de artistas do qual fazia parte, a Judson Church Theater, atribuindo suas inovações artísticas a este período. Anne Bogart conheceu Mary Overlie em 1979 na Universidade de Nova Iorque e lá tomou contato com o seu modo próprio de estruturar tempo e espaço na improvisação em dança, que Overlie aplicava não somente na composição coreográfica como na sua metodologia de ensino. Bogart entendia que "a abordagem de Mary para gerar movimento para o palco era aplicável para criar momentos visceralmente dinâmicos no teatro com atores e outros colaboradores" (p. 07). Em 1987, quando Bogart conheceu Tina Landau no American Repertory Theatre, em Massachusetts, desenvolveram gradativamente um trabalho colaborativo ao longo de dez anos com os Six Viewpoints de Overlie aplicados ao teatro, expandindo para os nove Viewpoints físicos (andamento, duração, relacionamento espacial, repetição, resposta sinestésica, forma, gesto, topografia e arquitetura), como são conhecidos atualmente, além de sistematizarem outros cinco Viewpoints vocais (altura, volume, dinâmica, aceleração/desaceleração e pausa).

${ }^{8}$ Transcrição de trecho do relatório da aula de 26 de setembro de 2007, feito pelo aluno Pedro de Souza.
} 
corpo, o corpo do outro, a relação destes corpos no mesmo espaço, a consciência do trabalho em grupo, ajuda mútua, cooperação e a influência deste trabalho no convívio cotidiano.

\begin{abstract}
A aula de hoje tem tudo a ver com o nosso dia-a-dia, aprendemos o trabalho coletivo de andar juntos tentar ficar em sincronização com o companheiro! E na aula passada fizemos praticamente as mesmas coisas só mudamos os exercícios, mas trabalhamos coletivamente como hoje! Quase chegamos lá: nem todos nós conseguimos o objetivo certo, algumas pessoas iam rápido demais outras devagar. Mas para mim as aulas com o Professor Fabiano estão sendo maravilhosas, estou aprendendo a trabalhar coletivamente, algo que para mim era quase impossível!!
\end{abstract}

Esta experiência me proporcionou a oportunidade de falar de corpo e de corpos evitando associações pornográficas, referência direta quando se pronunciam essas palavras na sala de aula entre adolescestes e absolutamente desnecessárias naquele ambiente.

A professora regente da disciplina de Artes da escola era Priscila Mesquita, então graduanda em Artes Cênicas pela UDESC e contratada temporariamente pela Prefeitura Municipal de Florianópolis como professora substituta. $\mathrm{O}$ fato de conhecê-la anteriormente como colega da Universidade me ajudou a discutir abertamente propostas metodológicas e trocar experiências de aulas, sem receio da privação de palavras e exposição das opiniões - fatores que, acredito, teria que vencer caso não conhecesse a Priscila ou se fosse uma professora desatualizada e pouco receptiva a novas ferramentas de ensino de artes na escola.

Aproveitando esta aproximação, conversamos sobre o comportamento dos alunos da turma 81 durante as aulas de Artes, na ocasião onde fui assistir a uma aula dela, uma semana antes de começar o meu estágio. Minhas conclusões se assemelham ao que Priscila já havia me adiantado.

Os alunos da turma 81 têm entre treze e dezesseis anos, são moradores dos bairros da região da Lagoa da Conceição e pouco familiarizados com as artes. $\mathrm{Na}$ verdade eles dialogam com as artes num âmbito mais abrangente, tais quais filmes de sucesso do momento, como o nacional Tropa de Elite - muito comentado nas aulas, músicas em formato $M p 3$ e livros de grande tiragem e apelo comercial, como os da série Harry Potter. Assim como a maioria dos adolescentes em idade escolar, poucos conhecem teatro, seja o edifício, seja a arte do teatro ou outras artes cênicas, exceto as danças que passam na televisão e o Cirque du Soleil (LODI, 2007, p. 04).

Preocupado com a abordagem a ser adotada ao constatar este perfil, propus à professora Priscila dividir a turma em dois grupos. Cada um de nós trabalharia com uma

\footnotetext{
${ }^{9}$ Transcrição de trecho do relatório da aula de 26 de setembro de 2007, feito pela aluna Brisa Caroline.
} 
parte da turma a cada quarta-feira, o que facilitou o trabalho de ambos, visto que a turma 81 era composta por aproximadamente 35 alunos.

A meta principal era conquistar a confiança dos alunos e construir no grupo a idéia de que a arte não é algo distante ou para poucos e sim uma possibilidade de expressão, conhecimento e compreensão das relações sociais. Não quero dizer, entretanto, que não relacionei os conteúdos trabalhados nos encontros. Isso felizmente aconteceu. As aulas foram relembradas sem o necessário compromisso de dependência uma da outra.

Para elaborar os planos de aulas busquei apoio em outras fontes além dos Viewpoints. Num primeiro momento recorri aos jogos dramáticos de Maria Clara Machado (1996), nas dinâmicas espaço-temporais de Rudolf Laban (1978) e nos exercícios de reeducação do movimento e conscientização do espaço e do corpo, de Ivaldo Bertazzo (2004).

No decorrer das aulas percebi que poderia experimentar outras práticas não pensadas previamente neste projeto, mas que fazem parte da minha experiência pessoal como artista. Adicionei exercícios desenvolvidos pelo $\mathrm{LUME}^{10}$ contidos no livro de Renato Ferracini (2001), com apoio na Antropologia Teatral, de Eugenio Barba (1994). Não estabeleci um critério de como - em que momentos - utilizar este ou aquele, já que foram referências que vieram depois e complementaram os planos de aula previamente elaborados.

Com as propostas de Bertazzo (2004) os alunos puderam ter contato mais específico com a qualidade de movimento de seus corpos, sua origem, suas limitações e possibilidades. Encarei o desafio ciente de que o adolescente tem dificuldade em se concentrar na percepção do corpo, fato inerente a esta faixa etária, o que é "perfeitamente saudável”, como diz Bertazzo. "O adolescente irrequieto já está na fase de demanda, revelando uma qualidade de tônus, de emotividade e de personalidade, que já solicita o movimento" (BERTAZZO, 2004, p. 60).

Uma vez escolhidas as referências, busquei trazer ao contexto de sala de aula exercícios que despertassem a atenção para suas atividades cotidianas além da escola, servindo como ponto de conexão com suas próprias vidas, incentivando-os a se perguntarem: como os esportes que pratico têm a ver com isso que estou fazendo agora? Como meu corpo se comporta em diferentes atividades? Por que é tão difícil não falar durante os exercícios? O que muda no comportamento do grupo quando fazemos o mesmo exercício, uma vez com 15 , outra com 30 pessoas?

\footnotetext{
${ }^{10}$ Núcleo Interdisciplinar de Pesquisas Teatrais da UNICAMP, um dos mais expressivos grupos de teatro do Brasil, com sede em Campinas/SP.
} 
Com os exercícios de Viewpoints consegui deixar mais evidente que fazer teatro não é somente ter uma personagem ou fazer uma cena. A arte teatral aborda campos e questões que vão além da "simples" relação ator-personagem, relação esta presente de maneira rígida na idéia de teatro que os alunos têm. Os Viewpoints também são usados na preparação de atores e esta funcionalidade pretendia ser (e foi) mais evidente do que um mecanismo visando resultado artístico para apresentar no final do ano (ou do estágio). Exemplo disso são as incansáveis "pecinhas" temáticas que alunos e professores de Artes são, muitas vezes, obrigados a fazer, contrariamente a suas vontades ou mesmo ao curso natural das aulas, somente para agradar à direção da escola ou para provar que estão fazendo teatro.

Mesmo não fazendo uso de todas as referências auxiliares planejadas anteriormente, apresento-as aqui do modo como as pensei para enriquecer o conteúdo das aulas e variar o repertório. Escolhi exercícios dramáticos de Maria Clara Machado por trazerem jogos criativos que exploram situações do cotidiano de adolescentes desta faixa etária e por se tratar de uma autora reconhecida por suas obras destinadas ao universo infantil, sobretudo textos teatrais. Isso faz de Machado uma autora menos comum para lidar com o público adolescente, devido à idéia de que seus jogos teatrais, bem como seus textos, são voltados somente para crianças.

Além disso, creio que a recorrente utilização da autora Viola Spolin na sala de aula limita o repertório do professor. Não questiono a qualidade dos exercícios, mesmo porque os jogos de Spolin possuem uma fundamentação própria ao ensino de teatro, ao contrário dos Viewpoints. O meu questionamento se refere à utilização de metodologias de ensino de teatro na escola como se fossem cartilhas mágicas que resolvem qualquer plano de aula. Viewpoints e outras práticas levadas para a escola correm este risco. Deste modo, se faz necessário estimular cada vez mais o profissional da arte-educação ao uso consciente de variadas metodologias de ensino de teatro e por períodos mais extensos do que eu tive oportunidade, sempre atentos ao caráter educativo e de formação artística do cidadão que estas as técnicas possuem. Perguntas como essas fizeram parte das observações feitas em âmbito escolar durante os anos de graduação, principalmente nas disciplinas ligadas a pedagogia do teatro.

Este é um dos motivos mais explícitos para a escrita deste artigo: deixar claro que minha experiência com os Viewpoints não é uma receita de sucesso. Isso só é possível se houver sensibilidade, por parte do educador, de relacionar o conhecimento prévio dos alunos ao que você propõe trabalhar. Cléo Miranda e Nilza Veronesi (2004), assistente 
social e educadora corporal, respectivamente, no projeto Dança Comunidade, fazem um importante aporte sobre este tema.

\begin{abstract}
Cumprir o papel de educador não é apenas ensinar uma técnica, mas ter o olhar voltado para o cidadão como um todo. Ouvir, dar atenção, tocar, sorrir, ter paciência, ser solidário, acreditar, respeitar as diferenças, ter flexibilidade diante das diferentes situações: esses aspectos, fundamentais na reflexão sobre o papel do educador, devem fazer parte do cotidiano dos monitores, durante todo o processo (MIRANDA e VERONESI, 2004, p. 81).
\end{abstract}

Durante o estágio passei por diversas situações que mereceriam certamente ser relatadas, entretanto me atentarei a dois fatos marcantes nesta trajetória. Em determinada aula, pretendia trabalhar qualidades presentes no corpo masculino e feminino. Para isso, adaptei dois exercícios descritos no livro A arte de não interpretar como poesia corpórea do ator, de Ferracini (2001), denominados Samurai e Gueixa, objetivando em sala de aula a relação dos meninos em trabalhar com a energia feminina e vice-versa, baseado no que Barba (1994) chama de Anima $^{11}$ e Animus $^{12}$. A proposta era trabalhar a energia Anima com o exercício da Gueixa exercitado por meninos e energia Animus com o exercício do Samurai exercitado por meninas. ${ }^{13}$

Isso trouxe à tona um problema que o professor de Artes não dá conta, mas pode colaborar: a aceitação no grupo. "Quando tentei começar a Gueixa, a reação dos meninos foi imediata: negação" (LODI, 2007, p. 31). Já as meninas “[...] trabalharam a energia masculina e isso se deu muito bem. Todas se mostravam interessadas e disponíveis em fazer os movimentos fortes e precisos do Samurai" (Idem, Ibidem). Isso daria um campo excelente de discussão de vários aspectos filosóficos, sociais, culturais, artísticos, de gênero, entre muitos outros. $\mathrm{O}$ que importa no relato deste caso é a atitude que se toma diante de um ocorrido como este.

Decidi mudar os planos e me vi obrigado a reforçar estereótipos: os meninos então fizeram o Samurai, contrariando a idéia original discutida com minha orientadora. ${ }^{14}$

\footnotetext{
${ }^{11}$ Energia suave e delicada.

${ }^{12}$ Energia forte e vigorosa.

${ }^{13}$ Barba (1994) afirma que as energias Anima e Animus são dois pólos distintos de energia, duas temperaturas que somos tentados a confundir com a polaridade dos sexos. São termos que não têm nada que ver com a distinção masculino-feminina, nem com arquétipos de Jung. Referem-se a uma polaridade pertinente à anatomia do teatro, difícil de definir com palavras, portanto difícil de analisar, desenvolver e transmitir. Entretanto, no contexto apresentado, foi inevitável não associar diretamente a energia Anima à figura feminina da Gueixa e a energia Animus à figura masculina do Samurai e suas diretas representações em seus comportamentos sociais.

${ }^{14}$ Marisa Naspolini me orientou a valorizar as distintas qualidades de energia e sempre tomar cuidado para não estereotipar as qualidades de cada energia presente no Samurai e na Gueixa. [...] me lembrou que a tendência dos alunos é generalizar e usar as ferramentas dadas, neste caso, com outras finalidades, para o exibicionismo ou como motivo para fazer piadas dos colegas depois. Isso acontece principalmente entre os meninos (LODI, 2007, pp. 31-32).
} 
Mesmo assim, respostas interessantes apareceram nos relatórios. "Eu achei o Samurai idiota no começo, mas eu percebi que não se deve 'julgar o livro pela capa' e comecei a colaborar com a aula"15. Qualidades de movimento me pareceram claras para alguns alunos a partir dos exercícios dados. "No exercício do Samurai podemos ver que o movimento que fizemos não é igual ao que nós fazemos no nosso dia-dia" ${ }^{16}$.

Outra situação que me cabe relatar me acompanhou por todo o estágio e foi pauta em muitas reuniões de orientação. Comecei a perceber alguns comportamentos inapropriados na sala de aula por parte de alguns alunos, sendo:

[...] garotas que nunca paravam de falar e não realizavam os exercícios devidamente; o casal de "ficantes" que se provocava durante minhas explicações [...] a violenta reação dos garotos a um colega com dificuldades de realizar os exercícios, que [...] demonstrava um histórico de repressão por parte deles e uma deficiência em alguns aspectos motores. [...] Há o fato da "aluna-shopping", que chega toda montada para a escola, sempre atrasada e nunca participa de nada, mas por si só chama atenção de todos pelo modo como se veste (como se estivesse num shopping) (LODI, 2007, p. 23).

Foi um momento desesperador. O caso mais complicado foi o do aluno que apanhava dos outros colegas. A repressão acontecia de várias maneiras, desde agressões físicas como chutes, socos e "pedala Robinho" ${ }^{17}$ até xingamentos, como "poço de banha" e "Shrek". E, creio eu, isto não acontecia somente em minha aula, pois já parecia um fato comum, tanto para quem agredia como para ele, que sofria a repressão. Penso hoje que a orientação dada pela Marisa para pôr fim a esta situação foi a mais acertada, sendo esta a atitude que tomei e que minimizou o fato nas demais aulas.

[...] dar um basta na situação de maneira enérgica e enfatizar que na minha aula esse tipo de atitude não pode acontecer. Reforçar que não se deve ter essa atitude em nenhuma outra situação e aproveitar para relacionar este fato ao cuidado com o corpo do outro, a noção de respeito com o seu espaço e o espaço do próximo, o tempo de cada um, a tolerância e paciência com as dificuldades alheias. Devo insistir em caso de resistência por parte deles já que se trata de uma atitude comum (Idem, p. 24).

Concluo minhas observações verificando que, nesta experiência, propus uma prática que possibilitou pensar como o corpo "pensa" quando age, fazendo dele um agente de autotransformação, transformação social e de experimentação estética da arte teatral.

\footnotetext{
${ }^{15}$ Transcrição de trecho do relatório da aula de 17 de outubro de 2007, feito pelo aluno Marcelo Bitencourt.

${ }^{16}$ Transcrição de trecho do relatório da aula de 17 de outubro de 2007, feito pela aluna Daniely Couto.

${ }^{17}$ Agressão muito comum entre adolescentes desta faixa etária, onde é dado um tapa na nuca do outro seguido da frase "pedala Robinho".
} 
Eleger o corpo como foco de trabalho educativo na escola através dos Viewpoints representou para mim investimento em uma nova jornada na minha experiência profissional e como estudante universitário, ao mesmo tempo em que se configurou uma prática inédita no âmbito escolar (não somente) em Florianópolis.

O entendimento do corpo através da disciplina de Artes na escola pode e deve ser uma oportunidade de vivência artística, aprendizado e autoconhecimento, fazendo do ambiente escolar um local que ofereça subsídios para se pensar o mundo através do corpo, a cidadania através da arte e os Viewpoints como prática teatral.

\section{REFERÊNCIAS BIBLIOGRÁFICAS:}

BARBA, Eugenio. A canoa de papel. Tratado de Antropologia Teatral. Tradução de Patrícia Alves. São Paulo: Editora Hucitec, 1994.

BERTAZZO, Ivaldo. Espaço Vazio e Mandala. In: Espaço e corpo: guia de reeducação do movimento. São Paulo: SESC, 2004, pp. 57-72.

BOGART, Anne; LANDAU, Tina. The Viewpoints book. A practical guide of Viewpoints and composition. New York: Theatre Comunications Group, 2005.

FERRACINI, Renato. A arte de não interpretar como poesia corpórea do ator. Campinas, SP: Editora da Unicamp, Imprensa Oficial do Estado S.A. - IMESP, 2001.

LABAN, Rudolf; ULLMANN, Lisa. Domínio do movimento. $4^{\text {a }}$ edição. São Paulo: Summus, 1978.

LODI, Fabiano. Relatório final de Estágio III. Florianópolis, 2007.

MACHADO, Maria Clara. 100 jogos dramáticos: teatro. $2^{\text {a }}$ edição. Rio de Janeiro: Agir, 1996.

MIRANDA, Cléo Regina; VERONESI, Nilza Assumpção. Espaço Exterior - Vínculos com o Hábitat. In: BERTAZZO, Ivaldo. Espaço e corpo: guia de reeducação do movimento. São Paulo, SESC, 2004, pp. 75-87.

MIRANDA, Danilo Santos de. Processo educativo na ação cultural. In: BERTAZZO, Ivaldo. Espaço e corpo: guia de reeducação do movimento. São Paulo, SESC, 2004, pp. 05-06.

SPOLIN, Viola. O jogo teatral no livro do diretor. São Paulo: Perspectiva, 1985.

\section{OUTROS:}

GODOY, Aldo Alberto; BRANCHER, Maty Lice; THOMAZ, Juliano Farias. Guia para apresentação de trabalhos acadêmicos. $2^{a}$ Edição Revisada. Orientação e revisão Tereza Mara Franzoni. Encadernado. Florianópolis, 2007. 
RELATÓRIOS DE AULA DE ARTES. Turma 81 da Escola de Educação Básica Henrique Veras. Florianópolis, 2007. 